\section{(B) OPEN ACCESS}

\title{
A luminance-based heart chip assay for assessing the efficacy of graft preservation solutions in heart transplantation in rats
}

\author{
Masashi Maeda, Naoya Kasahara, Junshi Doi, Yuki lijima, Takeshi Kikuchi, \\ Takumi Teratani, Eiji Kobayashi
}

Division of Development of Advanced Therapy, Center for Development of Advanced Medical Technology, Jichi Medical University, Tochigi, Japan

\section{Correspondence to}

Dr Takumi Teratani, Division of Development Advanced Therapy, Center for

Development of Advanced Medical Technology, Jichi Medical University, 3311-1, Yakushiji, Shimotsukeshi, Tochigi 329-0498, Japan; teratani@jichi.ac.jp

MM and NK contributed equally

Received 1 August 2012 Revised 29 November 2012 Accepted 9 December 2012
To cite: Maeda M, Kasahara N, Doi J, et al. Heart Asia Published Online First: [please include Day Month Year] doi:10.1136/ heartasia-2012-010160

\section{ABSTRACT \\ Objective We developed a novel luciferase-based viability assay for assessing the viability of hearts preserved in different solutions. We examined whether this in vitro system could predict heart damage and survival after transplantation in rats.}

Design By our novel system, preserved heart viability evaluation and transplanted heart-graft functional research study.

Setting University basic science laboratory.

Interventions Isolated Luciferase-transgenic Lewis (LEW) rat cardiac-tissue-chips were plated on 96-well tissue-culture plates and incubated in preservation solutions at $4^{\circ} \mathrm{C}$. Viability was measured as photon intensity by using a bio-imaging system. Heart-grafts preserved in University of Wisconsin (UW), extracellular-trehalose-Kyoto (ETK), EuroCollins (EC), histidin-tryptophan-ketoglutarat solution (HTK), lactated Ringer's (LR) or normal saline solution were transplanted cervically by using a cuff-technique or into the abdomens of syngeneic wild-type LEW rats by using conventional microsurgical suture techniques.

Main outcome measures Imaging an evaluation of preservation heart-graft and functional analysis.

Results Cardiac-tissue-chips preserved with UW, HTK or ETK solution gave higher luminance than those preserved with EC, LR or normal saline $(p<0.03)$. After $24 \mathrm{~h}$ of preservation of hearts in each solution at $4^{\circ} \mathrm{C}$, the beating of the isolated hearts was evaluated. The success rate, evaluation of beating, of cervical heart transplants using UW and ETK solution exceeded 70\%, but those using other preservation solutions were lower (UW: 100\%, ETK: $75 \%$, EC: $42.86 \%$, HTK: $14.29 \%$, normal saline: $0 \%$ ).

Histological analysis of cervical heart-grafts after $3 \mathrm{~h}$ preservation by myeloperoxidase (MPO), zona occludens-1 (ZO-1), and caspase-3 immunostaining revealed different degrees of preservation damage in all grafts.

Conclusions Our novel assay system is simple and can test multiple solutions. It should therefore be a powerful tool for developing and improving new heart-graft preservation solutions.

\section{INTRODUCTION}

Heart transplantation remains the gold standard in the treatment of end-stage congestive heart failure. Treatment for heart failure continues while patients await transplants, and because no one can predict the timing of donation, the transplant team must always be available at short notice. Furthermore, proximity of the donor and recipient teams is important, because the permissible ischaemic time for the heart is shorter than those of other organs. ${ }^{1}$ Heart preservation for transplantation is limited to
4-6 h of cold ischaemic storage; longer periods of ischaemia adversely affect survival. ${ }^{2-4}$ Generally, the use of University of Wisconsin (UW) or Celsior solution has been suggested for extended organ preservation beyond $4 \mathrm{~h}$ in clinical and experimental cardiac transplantation. ${ }^{5-7}$ Cold ischaemia times ranging from 12 to $30 \mathrm{~h}$ are acceptable in kidney transplantation, but they are unacceptable in the transplantation of hearts preserved in UW solution. Donor heart shortages have now become a critical issue worldwide. ${ }^{8}{ }^{9}$ To ensure that all of those hearts that do become available are used, it is therefore essential that we develop better preservation solutions that can preserve heart-grafts well for long periods of time. ${ }^{1011}$

Maintenance of high-energy phosphorylated compounds such as adenosine tri-phosphate (ATP) has been correlated with minimal changes to cell structure and function during cold storage. ${ }^{12}$ In addition, ATP levels are inversely proportional to the length of the preservation period. ${ }^{13}$ The $\mathrm{Na}^{+} / \mathrm{K}^{+}$ transporter maintains the respective gradients of these ions, relying on the use of ATP as its energy source. ${ }^{14}$ There is a significant relationship between ATP levels during preservation and the recovery of systolic function. ${ }^{15}$ One of the essential factors for the success of intestinal graft transplantation under cold ischaemic conditions is therefore the ability of the preservation solution to maintain ATP levels. ${ }^{16}$ The cell death mechanism appears to be ATP-dependent: ATP is required for execution of the apoptotic programme, whereas complete ATP depletion leads to necrosis. ${ }^{17} 18$

In our earlier reports, we demonstrated the use of a luciferase transgenic (Luc-Tg) rat system together with optical imaging techniques to better understand transplantation in the islets, kidney and intestine. ${ }^{19-23}$ Here, we developed a luciferasebased cell viability assay for heart chips obtained from Luc-Tg rats. Using this luciferase-based viability assay of rat hearts in multi-well plates, we first compared several preservation solutions (UW, extracellular-trehalose-Kyoto solution (ETK), EuroCollins (EC), histidin-tryptophan-ketoglutarat solution (HTK) and normal saline (NS)). Hearts preserved in these solutions were then transplanted and their viability was examined in vivo.

\section{MATERIALS AND METHODS \\ Animals}

All experiments were performed in accordance with the Jichi Medical University Guide for Laboratory Animals. The luciferase-expressing transgenic Lewis 
rat line (Luc-Tg LEW rat, 8-weeks-old, female) was established in our laboratory as described previously. ${ }^{19} 20$

\section{Cellular ATP level assay}

Luc-Tg LEW male rat-derived cardiomyocytes were weighed and then extracted $1: 5 \mathrm{w} / \mathrm{v}$ in perchloric acid containing $1 \mathrm{mM}$ EDTA. The precipitated protein was removed by centrifugation $(20 \mathrm{~min}$ at $20000 \times g)$. Acid extracts were neutralised by the addition of $3 \mathrm{M} \mathrm{KOH}-0.4 \mathrm{M}$ Tris- $0.3 \mathrm{M} \mathrm{KCl}$ and then recentrifuged $(20 \mathrm{~min}$ at $14000 \times g)$. Spectrophotometric analysis was then performed to measure the absorbance of monodehydroascorbate reductase at a wavelength of $340 \mathrm{~nm}$, thus quantifying ATP. Values are reported per gram wet weight.

\section{Heart transplantation}

Wild-type LEW male rats, 8 weeks old, were used as donors and wild-type LEW male rats were used as recipients. Cervical heart transplantation was performed by using a cuff technique, as described previously. ${ }^{24}$ Animals were anaesthetised by intramuscular injection of $5 \mathrm{mg} / \mathrm{kg}$ xylazine (Bayer Yakuhin, Tokyo, Japan) and $100 \mathrm{mg} / \mathrm{kg}$ ketamine (Daiichi Sankyo, Tokyo, Japan). In the donor rat, the costal arch was amputated bilaterally with Cooper scissors. Next, the inferior vena cava and superior vena cava were ligated and cut, and then the descending aorta and pulmonary artery (PA) and pulmonary vein were cut after being tied with 4-0 silk. The preserved heart-graft was moved from the donor body after severance of the descending aorta and PA. It was then washed in NS containing heparin (1000 IU) and soaked in the chosen preservation solution for $24 \mathrm{~h}$ at $4^{\circ} \mathrm{C}$. In the recipient rat, the right external jugular vein (EJV) was exteriorised on the body surface. After a 4-0 silk ligature had been tied, a cuff was connected peripheral to the ligature and the EJV was then cut. Next, the carotid artery was exteriorised from the right sternomastoid muscle and ligated peripherally by using 4-0 silk and a cuff. The cut end of each blood vessel in the recipient rat was washed in NS containing heparin (1000 IU). The graft's PA was connected to the recipient's right EJV after anastomosis of the graft's ascending aorta and the recipient's carotid artery by using the cuff after preserved $24 \mathrm{~h}$.

In a separate experiment, preserved heart-grafts in preservation solutions were transplanted into the abdomens of syngeneic wild-type LEW male rats by using a conventional microsurgical suture technique. ${ }^{25}$ The heparinised recipient rats $(1 \mathrm{ml} / \mathrm{rat}$ (1000 IU): Mitsubishi Tanabe Pharma Corporation, Osaka, Japan), which had received grafts preserved under cold conditions $\left(4^{\circ} \mathrm{C}\right)$ for $1 \mathrm{~h}$, were euthanised $3 \mathrm{~h}$ after re-establishment
Figure 1 Preparation of luciferase transgenic (Luc- Tg) rat cardiac tissue chips for in vivo imaging. All preparation was done in a cold room. (A) Tissue chip-making system. (B) Several sizes of cardiac tissue chip (about 3-8 mm). (C) Cardiac tissue chip assay plate for in vivo imaging system and/or ELISA analysis. (D) Luc-Tg rat-derived cardiomyocyte viability, as measured by cellular ATP concentration and bioluminescence imaging using the in vivo imaging system. After photon count, cellular ATP extraction was measured.
A

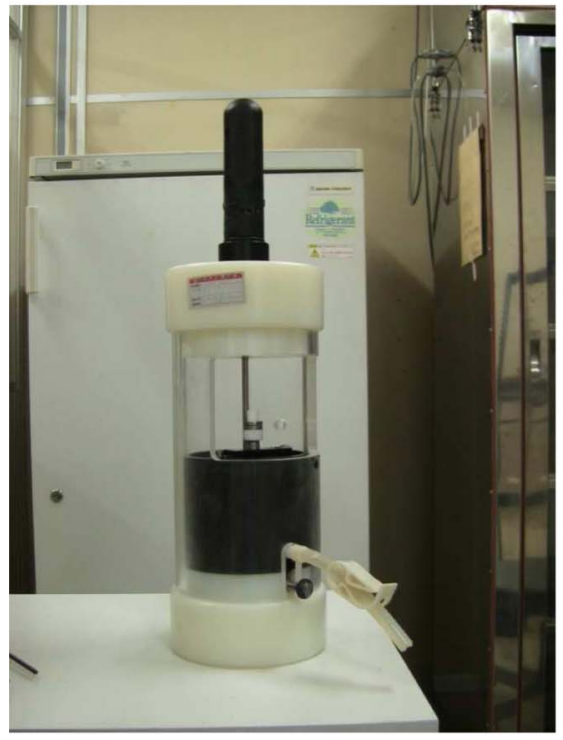

B

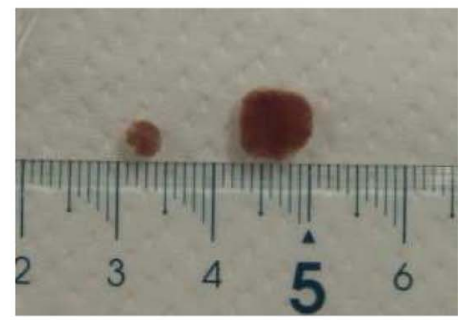

C

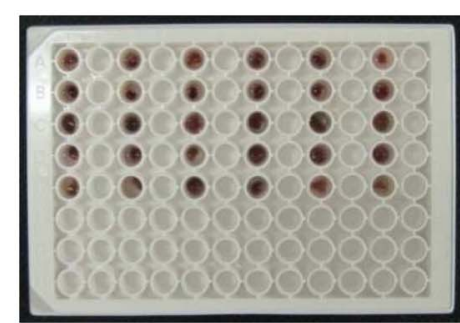

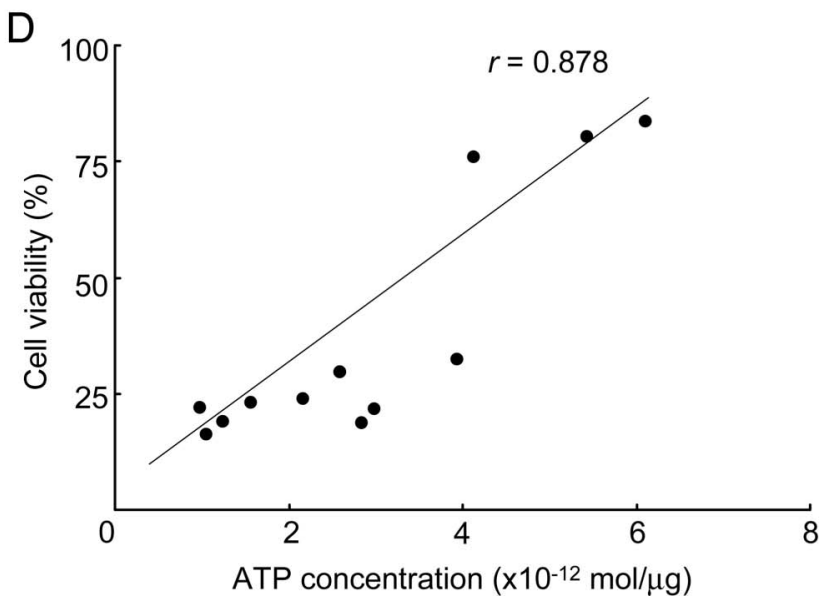


Table 1 Heart viability assessment

\begin{tabular}{|c|c|c|c|c|c|c|c|c|c|}
\hline Solution & $0 \mathrm{~min}$ & $10 \mathrm{~min}$ & $20 \mathrm{~min}$ & $30 \mathrm{~min}$ & $40 \mathrm{~min}$ & $50 \mathrm{~min}$ & $60 \mathrm{~min}$ & $70 \mathrm{~min}$ & $80 \mathrm{~min}$ \\
\hline UW & $100 \pm 0$ & $80.05 \pm 4.33^{c, d}$ & $58.19 \pm 6.18^{c, d}$ & $38.62 \pm 1.82^{c, d}$ & $32.37 \pm 1.21^{c, d}$ & $25.67 \pm 1.26^{c, d, e, f}$ & $24.75 \pm 1.60^{c, d, e, f}$ & $23.08 \pm 1.16^{c, d, e, f}$ & $21.28 \pm 1.31^{c, d, e, f}$ \\
\hline ETK & $100 \pm 0$ & $77.49 \pm 8.19^{c, d}$ & $54.41 \pm 7.61^{\mathrm{b}, \mathrm{c}}$ & $37.45 \pm 4.45^{\text {c.d }}$ & $29.83 \pm 3.51^{c, d}$ & $24.52 \pm 2.98^{c, d, e, f}$ & $21.77 \pm 2.78^{c, d, e, f}$ & $20.65 \pm 3.23^{c, d, e, f}$ & $19.96 \pm 2.51^{c, d, e, f}$ \\
\hline HTK & $100 \pm 0$ & $66.44 \pm 5.95$ & $47.20 \pm 10.01^{\mathrm{a}}$ & $29.04 \pm 4.54^{\mathrm{a}}$ & $21.45 \pm 5.80$ & $13.18 \pm 3.09$ & $8.70 \pm 1.66$ & $5.61 \pm 1.26^{b, c, d}$ & $5.61 \pm 0.63^{c, d, e, f}$ \\
\hline $\mathrm{EC}$ & $100 \pm 0$ & $74.50 \pm 3.35^{b, c}$ & $48.07 \pm 1.94^{\mathrm{a}}$ & $39.44 \pm 2.44^{c, d}$ & $28.44 \pm 2.18^{b, c}$ & $23.88 \pm 1.82^{c, d, e, f}$ & $20.87 \pm 1.10^{c, d, e, f}$ & $15.65 \pm 1.24^{\mathrm{e}}$ & $15.64 \pm 1.09^{\mathrm{e}}$ \\
\hline LR & $100 \pm 0$ & $39.45 \pm 7.08$ & $19.42 \pm 2.90$ & $11.35 \pm 1.95$ & $9.36 \pm 2.05$ & $7.73 \pm 1.74$ & $6.77 \pm 1.54$ & $5.18 \pm 0.97$ & $4.97 \pm 1.29$ \\
\hline Saline & $100 \pm 0$ & $42.56 \pm 6.31$ & $21.59 \pm 3.15$ & $17.41 \pm 3.22$ & $11.56 \pm 2.16$ & $9.81 \pm 2.19$ & $8.09 \pm 1.61$ & $6.57 \pm 1.28$ & $5.72 \pm 1.19$ \\
\hline
\end{tabular}

Bioluminescent imaging using the IVIS system assessed heart viability. All samples were exposed to organ preservation solutions and saline (control) at $4{ }^{\circ} \mathrm{C}$. Data are representative of seven independent experiments.

$p$ Values estimated by repeated measure one-way analysis of variance (ANOVA) and one-way ANOVA were a: $<0.05$ for $L R, b:<0.05$ for saline, $c:<0.01$ for $L R$, d: $<0.01$ for saline, e: $<0.05$ for HTK and f: $<0.01$ for HTK.

EC, Euro-Collins; ETK, extracellular-trehalose-Kyoto solution; HTK, histidin-tryptophan-ketoglutarat solution; IVIS, in vivo imaging system; LR, lactated Ringer's; UW, University of Wisconsin.

of flow for histological analysis of the transplanted hearts. The heart samples were suitable for immunohistochemical analysis. ${ }^{26}$ The warm ischaemic time of the hearts transplanted by using the cuff technique was about $5 \mathrm{~min}$, and that by using the conventional microsurgical suture technique was about $30 \mathrm{~min}$.
In vitro assay of heart viability in several preservation solutions

Freshly isolated Luc-Tg LEW male rat hearts were plated in 96-well tissue culture plates $(n=7$ each) and incubated in preservation solutions at $4^{\circ} \mathrm{C}$ for $0-80 \mathrm{~min}$. The preservation solutions
A

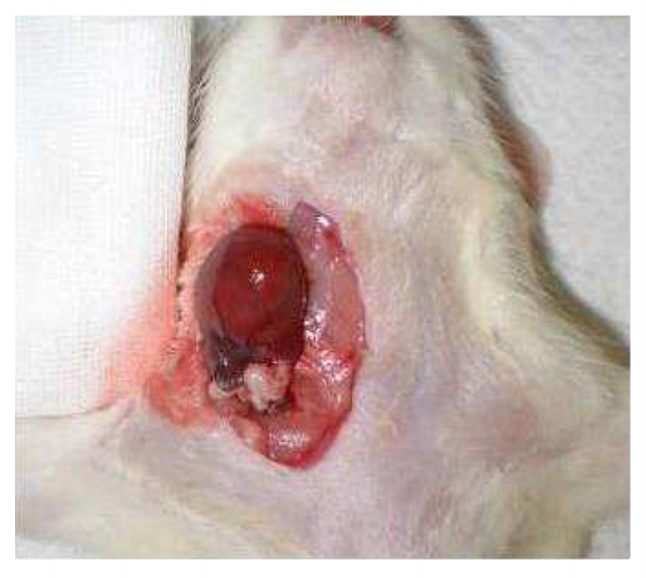

B

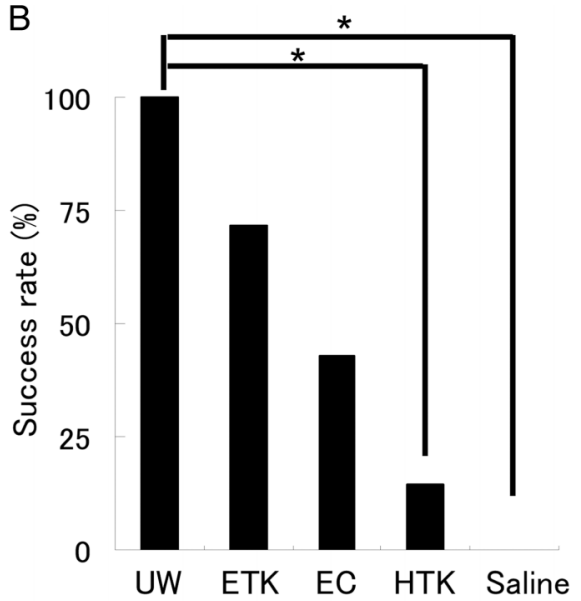

C
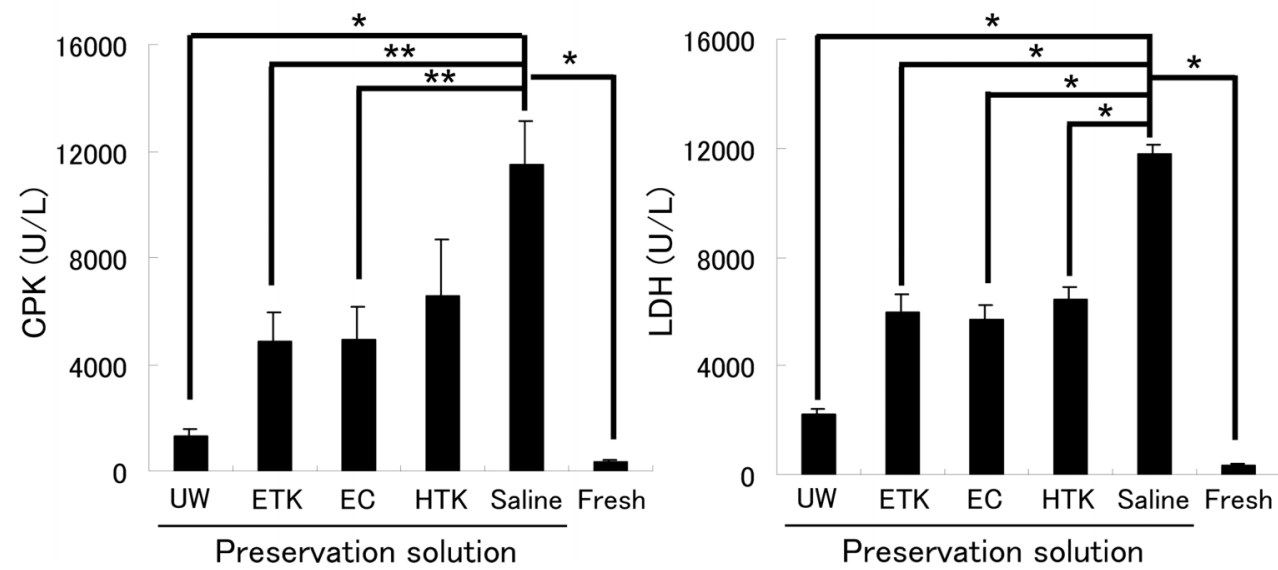

Figure 2 Cervical heart transplantation using the cuff technique after preservation of the heart in various different solutions at $4^{\circ} \mathrm{C}$. (A) Cervical heart transplantation performed using the cuff technique. (B) Evaluation of the beating rate of preserved heart-grafts $24 \mathrm{~h}$ after transplantation. (C) Analysis of heart injury markers (CPK and lactase dehydrogenase (LDH)) in the sera of rats that had received preserved heart transplants. ${ }^{*}<0.01$ for solution, ${ }^{* *}<0.05$ for solution by one-way analysis of variance. EC, Euro-Collins; ETK, extracellular-trehalose-Kyoto solution; HTK, histidin-tryptophan-ketoglutarat solution; UW, University of Wisconsin. 
used have been described previously. ${ }^{22}$ Detection was performed by addition of $22 \mu \mathrm{l} /$ well $(2.29 \mathrm{mg} / \mathrm{ml})$ of luciferase-based reagent (D-luciferin: Wako, Tokyo, Japan) by in vivo imaging system (Summit Pharmaceuticals International Co., Tokyo, Japan). To assess viability, hearts were mixed 1:1 with Trypan Blue solution (GIBCO, Tokyo, Japan) and the total cells and Trypan Blue-positive cells were counted within 3 min under a light microscope by using a haemocytometer.

\section{Measurement of myocardial injury enzymes}

Serum creatine phosphokinase (CPK) and lactase dehydrogenase $(\mathrm{LDH})$ were measured in recipient rat by using a Dri-Chem 4000 chemistry analyser with CPK-PIII Dri-Chem and LDH-PIII Dri-Chem slides, respectively (Fujifilm, Tokyo, Japan).

\section{Evaluation of heart-graft colour definition ratio after} and before transplantation

All preserved and transplanted heart-grafts were photographed with a digital camera (Power Shot A1100 IS, Canon, Tokyo,
Japan). Sample photographs were analysed to determine the colour definition ratios of the hearts by using Photoshop (Adobe, Tokyo, Japan) and Scion Image (NIH web site) software.

\section{Histological analysis of preserved hearts}

After the transplanted preserved hearts had been removed from the recipients, the hearts were fixed in $10 \%$ buffered formalin for paraffin embedding on glass slides. Paraffin-embedded sections were stained with hematoxylin and eosin (HE) for conventional morphological evaluation. Paraffin sections of hearts from rats sacrificed $3 \mathrm{~h}$ after reflow were prepared. The paraffin sections were analysed immunohistochemically by incubation with caspase- $3(1: 100)$ and zona occludens (ZO)-1 (1:100) antibodies overnight at $4^{\circ} \mathrm{C}$. Positive cells were detected by diaminobenzidine staining. Oxidative stress conditions were evaluated by the addition of antirat myeloperoxidase (MPO) conjugatedfluorescein isothiocyanate (FITC) antibody (1:50). MPO-positive cells were identified by FITC expression, which was monitored by fluorescence microscopy (Nikon, Tokyo,
A

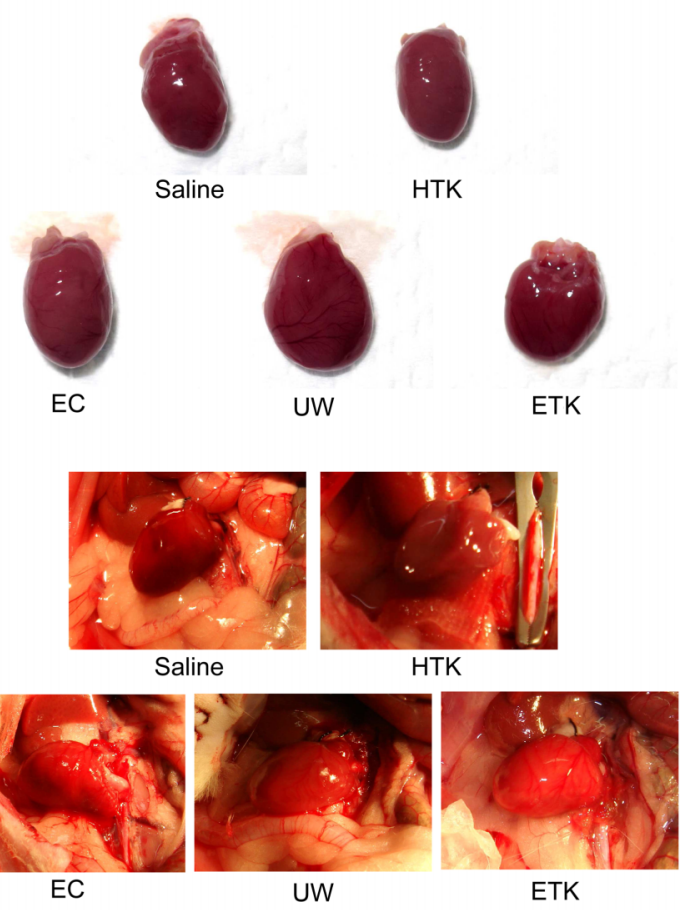

C

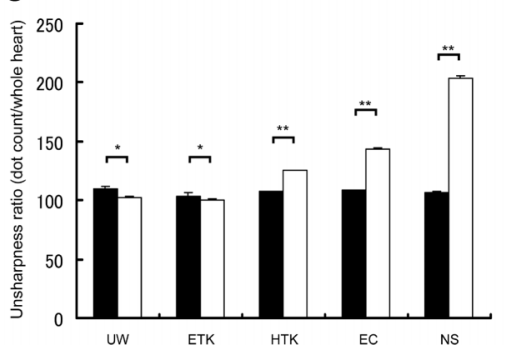

D

$\mathrm{x} 40$

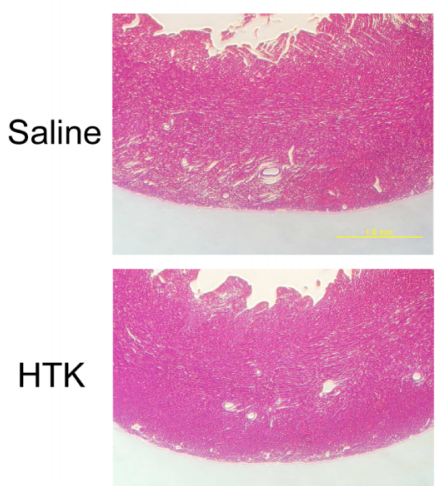

EC
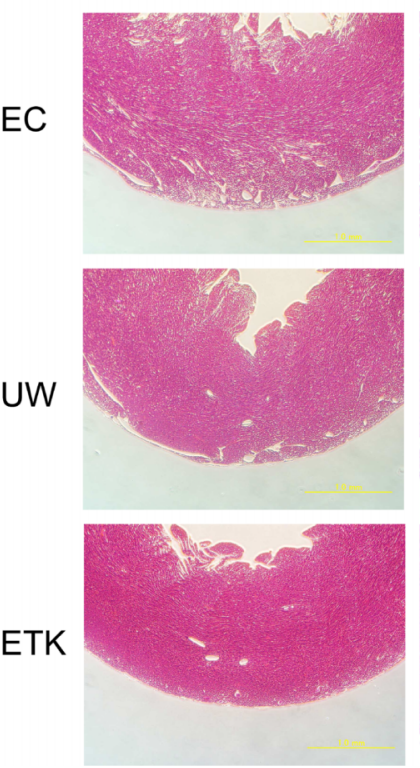

x200
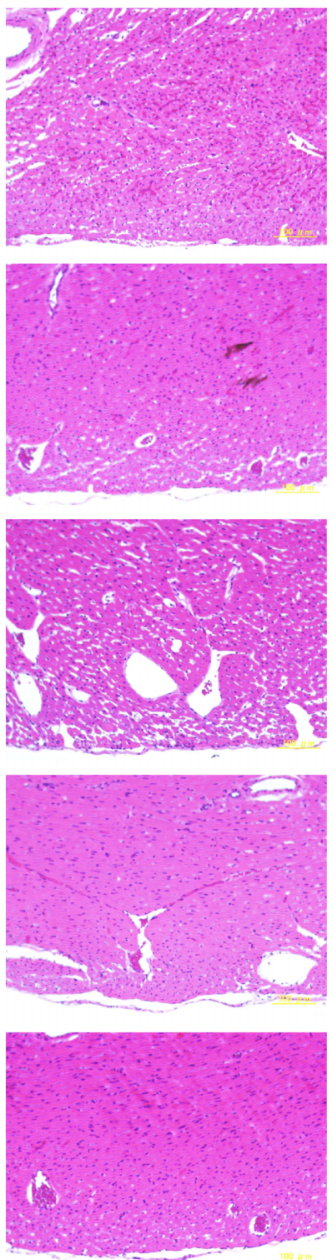

Figure 3 Preserved heart-grafts were transplanted into the abdomen using conventional microsurgical suture techniques. (A) Macroscopic appearance of grafted hearts preserved for $1 \mathrm{~h}$ at $4^{\circ} \mathrm{C}$. (B) Macroscopic appearance of heart-grafts $3 \mathrm{~h}$ after transplantation. (C) Macroscopic evaluation $3 \mathrm{~h}$ after transplantation of hearts that had been preserved for $1 \mathrm{~h}$; imaging software was used (Adobe Photoshop; NIH web site, Scion Image). White bars, before transplantation; black bars, $3 \mathrm{~h}$ after transplantation ( $n=3$ per solution; * $p>0.05$ and ${ }^{*}$ * $p<0.05$ ). (D) Morphological analysis by hematoxylin and eosin (HE) staining, apex area of transplanted hearts. (E) Atria area of transplanted hearts. Scale bars are $1 \mathrm{~mm}$. (F) Immunostaining evaluation of damage in transplanted hearts. Analysis of zona occludens (ZO)-1 expression levels using diaminobenzidine (DAB) staining. (G) Combination image of myeloperoxidase (green) and 4',6-diamidino-2-phenylindole (DAPI) (blue) staining. (H) Apoptosis-positivity of cells, as shown by using caspase-3 antibody and DAB staining. All imaging photograph scale bars are $200 \mu \mathrm{m}$. EC, Euro-Collins; ETK, extracellular-trehalose-Kyoto solution; HTK, histidin-tryptophan-ketoglutarat solution; NS, normal saline; UW, University of Wisconsin. 
Japan). All antibodies were purchased from Santa Cruz Biotechnology Inc. Immunostaining-positive cardiomyocytes were quantified by calculating the mean numbers of positive cells in 10 random $200 \times$ fields per animal.

\section{Statistical analysis}

Results are given as means \pm SEM. Student $t$ test was performed for statistical evaluation, with $\mathrm{p}<0.05$ considered significant. Where more than two samples were compared, one-way analysis of variance (ANOVA) statistical analysis was performed and the results are given as \pm SEM. Tukey-Kramer test was used in case of $p$ values less than 0.05 for one-way ANOVA. Pearson's product-moment correlation coefficient was used to study the relationship between ATP concentration and cell viability of preserved heart chip. Kruskal-Wallis test followed by Mann-Whitney $U$ test with Bonferroni's correction was used for analysis of success rate of heart transplantation.

\section{RESULTS}

\section{Effect of preservation solution on viability}

\section{of cardiac tissue chips}

Small tissue chips were placed at $4^{\circ} \mathrm{C}$ in the wells of 96 -well plates filled with different organ preservation solutions (figure $1 \mathrm{~A}-\mathrm{C}$, $\mathrm{n}=5$ plates per solution). The luminance of each sample was measured with a living imaging system (in vivo imaging system; table 1). Cardiac tissue chips preserved with UW, HTK or ETK solution gave higher luminance than those preserved with EC, LR
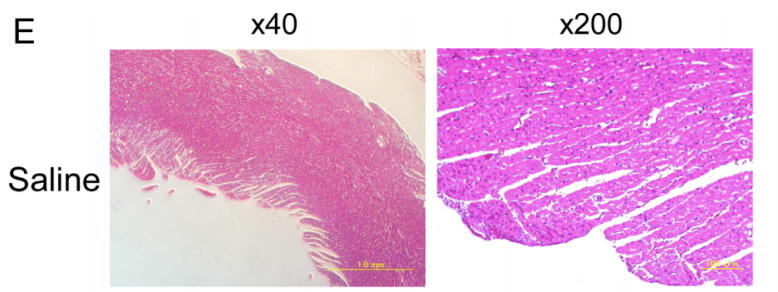

$\mathrm{F}$
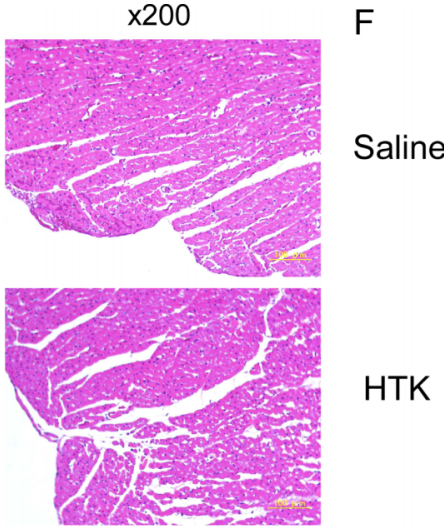

HTK

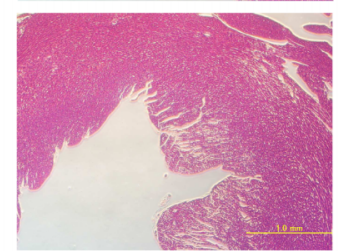

EC
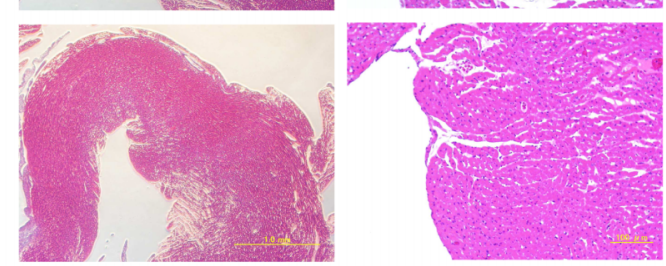

UW
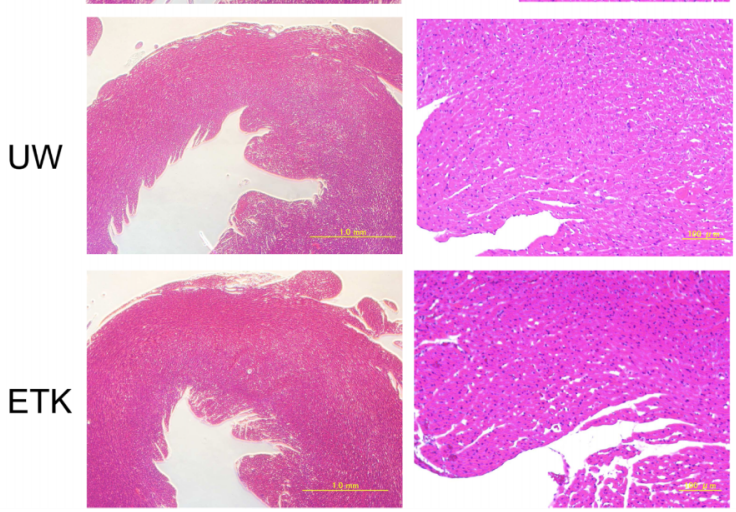

or NS. Chips preserved in UW or ETK solution had notably higher luminescence than those preserved in the other solutions; this finding was consistent with the higher levels of tissue ATP in these samples. There was a strong correlation between ATP concentration $(\mathrm{mol} / \mathrm{mg})$ and relative photon intensity as an indication of cell viability $(r=0.88)$ (figure $1 \mathrm{D})$. When a whole heart wall was used instead of a chip sample, the luminance was not significantly correlated with the content of tissue ATP (data not shown). Therefore, it is important to use chips of the heart wall for accurate evaluation of the state of preservation.

\section{Evaluation of preserved hearts transplanted into the right cervical region}

After $24 \mathrm{~h}$ of preservation in preservation solution at $4^{\circ} \mathrm{C}$, isolated hearts were transplanted heterotopically into the right cervical region (figure 2A). Twenty-four hours after the transplant, all preserved heart-grafts were evaluated by assessment of their beating. UW and ETK solutions had success rates of more than $70 \%$, whereas the other preservation solutions had low success rates (figure $2 \mathrm{~B}, \mathrm{n}=7 /$ solution). Three hours after reperfusion there was substantial necrosis in the preserved hearts. Average CPK and LDH release were significantly lower with the use of UW solution (CPK: $1319.5 \pm 273.3 \mathrm{U} / 1 ; \quad \mathrm{LDH}: \quad 2195.0 \pm 230.0 \mathrm{U} / \mathrm{l})$ than with other solutions (figure $2 \mathrm{C}, \mathrm{n}=7 / \mathrm{each}$ ). ETK solution (CPK: $4843.3 \pm 1100.6 \mathrm{U} / 1$; LDH: $5961.8 \pm 637.7 \mathrm{U} / \mathrm{l})$ gave about the same degree of damage as EC solution (CPK: 4894.2 $\pm 1290.0 \mathrm{U} / 1$; LDH: 5688.6 $\pm 510.5 \mathrm{U} / \mathrm{l})$.

Figure 3 continued 
G

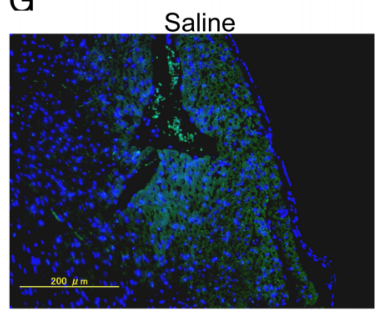

EC

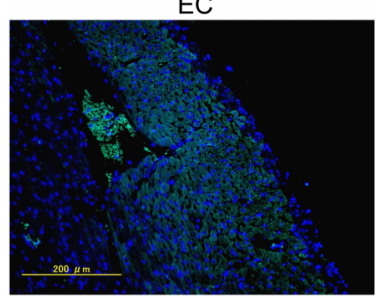

ETK

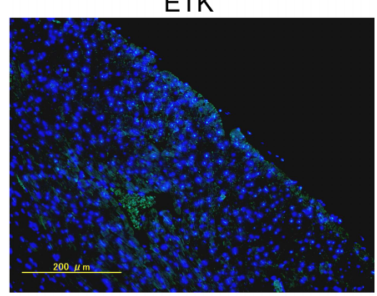

$\mathrm{H}$

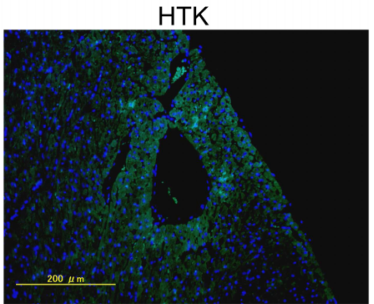

UW

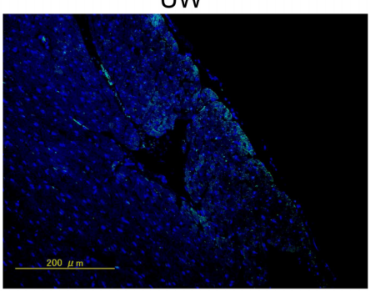

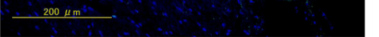

.

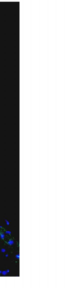

\section{Saline}

HTK
EC
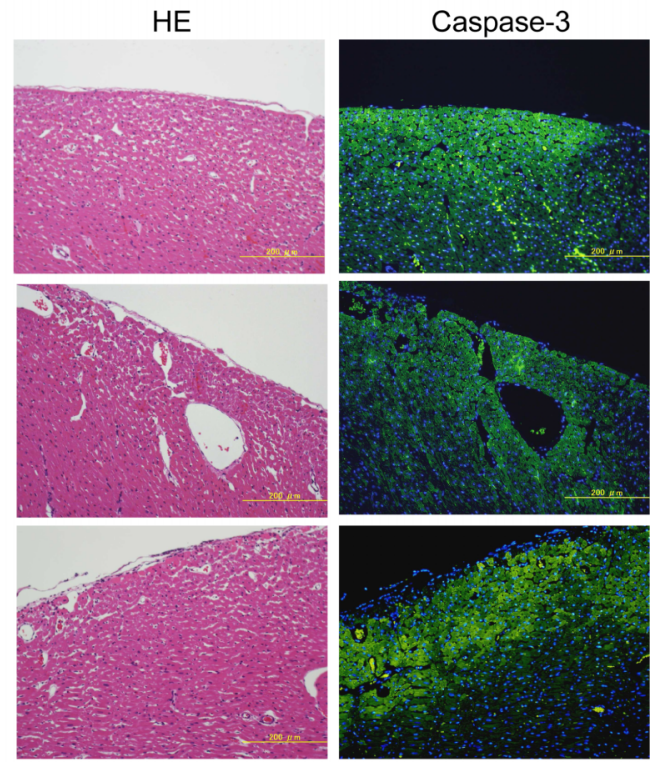

UW
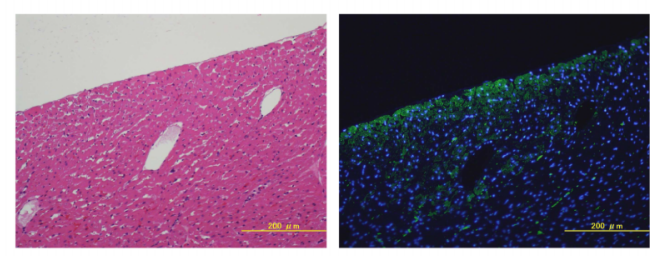

ETK
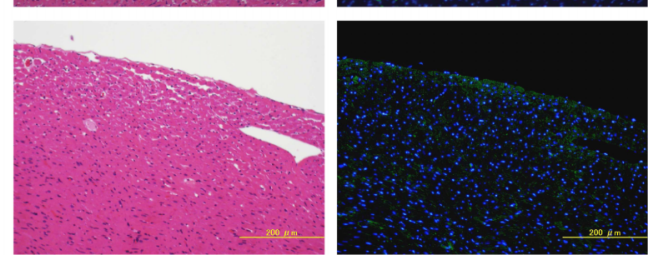

Figure 3 continued

\section{Analysis of myocardial histology after abdominal transplantation}

Next, to assess the cardiomyocyte damage caused by preservation, we evaluated the heart-grafts from some of the rats by assessing colour tone levels macroscopically and by H\&E staining microscopically (figure 3). Three hours after abdominal transplantation, heart-grafts that had been cold preserved for $1 \mathrm{~h}$ in UW, EC or ETK solution (figures $3 \mathrm{~A}$ and $\mathrm{C}$ ) were a brighter red than those preserved in HTK solution or NS (figures $3 \mathrm{~B}$ and $\mathrm{C}$ ). Transplanted heart beating rates were slightly worse $3 \mathrm{~h}$ after preservation in EC solution or NS (NS: $193.67 \pm 3.1$ beats $/ \mathrm{min} ; \quad$ EC: $212.33 \pm 3.6$ beats $/ \mathrm{min} ;$ HTK: $221.67 \pm 4.67$ beats $/ \mathrm{min}$; ETK: $272.67 \pm 3.83$ beats $/ \mathrm{min}$; UW: $277.33 \pm 2.78$ beats $/ \mathrm{min} ; \mathrm{n}=3 /$ each). Histological analysis revealed varying degrees of preservation damage in all heartgrafts. The apex area of the preserved heart showed marked injury in EC solution or NS (figure 3D); the atrial area was damaged in hearts preserved in HTK or EC solution or NS (figure 3E). Overall, histologically, cardiomyocyte damage was substantially less in UW or ETK preserved heart-grafts than in those preserved in other solutions or NS.

\section{Microscopic immunohistochemical analysis}

Hearts preserved in UW or ETK solution were strongly positive for the tight junction associated protein ZO-1 (figure 3F). Furthermore, the levels of MPO-positivity as a marker of oxidative stress were similar to those of the apoptosis marker caspase- 3 in the preserved heart-grafts and were lowest in the case of hearts preserved in UW or ETK (figure 3G, H, table 2). Thus, the effects of apoptosis, oxidative stress and failure of tissue structure inhibition were higher in hearts preserved in HTK or EC solution or NS than in those preserved in UW or ETK solution.

\section{DISCUSSION}

Heart transplantation is the final treatment option in heart failure, and transplant patients have substantially increased survival rates and quality of life. ${ }^{27}$ The first human-to-human heart transplantation was performed in South Africa in 1967, and by the end of 1968102 patients had received transplants at 52 institutions. ${ }^{1}$ However, the results were disappointing, with a $60 \%$ early death rate and a mean survival of only 29 days. ${ }^{28}$ In a large study in 2000, when the duration of cold ischaemia was $6 \mathrm{~h}$, graft survival at 3 years after surgery was nearly $25 \%$ less than that when the cold ischaemia period was $<2 \mathrm{~h}^{29}$

Use of organs from marginal donors has resulted in decreased graft function and survival compared with the use of organs from younger donors. ${ }^{30}$ It is currently difficult to obtain donor hearts. In addition, long-term outcomes for transplanted hearts are limited by the development of cardiac allograft vasculopathy resulting from immunological and non-immunological risk factors precipitated by injury to, and dysfunction of, the endothelium. ${ }^{31}{ }^{32}$ Current heart preservation strategies involving cardioplegic arrest and cold immersion in preservation solution 
Table 2 Preserved heart conditions assessment

\begin{tabular}{|c|c|c|c|c|c|}
\hline & UW & ETK & HTK & EC & Normal saline \\
\hline MPO & $4.231 \pm 1.423^{a, b, c}$ & $10.612 \pm 2.743^{a, c, d}$ & $52.754 \pm 12.531$ & $46.112 \pm 8.951$ & $63.028 \pm 13.742$ \\
\hline ZO-1 & $16.511 \pm 4.964$ & $28.813 \pm 7.328^{\mathrm{a}, \mathrm{e}, \mathrm{c}}$ & $8.613 \pm 2.868$ & $4.653 \pm 0.471$ & $2.971 \pm 0.162$ \\
\hline Caspase-3 & $7.129 \pm 3.851^{c}$ & $8.221 \pm 5.715^{c}$ & $27.821 \pm 10.251$ & $31.649 \pm 9.816$ & $29.275 \pm 11.776$ \\
\hline
\end{tabular}

have not changed substantially since long-distance transplantation procedures originated. ${ }^{33}$ The commonly preferred mode is cold storage at $4^{\circ} \mathrm{C}$, beginning with the rapid vascular washout of blood components by using ice-cold preservation solution. ${ }^{17}$ In addition, preserving the donor heart in a beating state ex vivo can safely prolong the preservation period. ${ }^{34}$

The somatic dimensions of several species of animals and of a wide variety of trees fit this rule well. It is a simple matter to show that energy metabolism during maximum sustained work depends on body cross-sectional area, not total body surface area. This finding, and the requirement for animal proportions to change with size, amount to a derivation of Kleiber's law, which correlates metabolically related variables with body weight. ${ }^{35}$ In the transplantation experiment using the cuff method, after cold preservation of the hearts for $24 \mathrm{~h}$, serum CPK and LDH levels were the highest in rats that had received hearts treated with NS (table 1 and figure 3C); we observed heart beating despite a poor correlation with tissue ATP concentration. The reason was that the myocytes in skeletal muscle were being used strongly for movement and were unaffected by the lysis of the cardiomyocytes (manuscript in preparation).

Tight junctions are found in many organisms and in many organs, including the skin, brain, lung, liver, testis and heart. They are located at the gaps between adjacent cells, joining their cytoskeletons, and are essential for the barrier function of the epidermis and endothelial cells. ${ }^{36}$ Lisewski and colleagues found in coxsackievirus-adenovirus receptor-knockout mice that the proper interplay of tight junctions determines the electrical properties of the adult heart. ${ }^{37}$ Importantly, in patients with heart failure due to dilated or ischaemic cardiomyopathy, areas of diminished ZO-1 expression are characterised by markedly reduced immunostaining. ${ }^{38}$ Therefore, because the level of positively for ZO-1 reflects heart function and viability, UW and ETK solutions preserved the heart well at $4^{\circ} \mathrm{C}$.

Given that mitochondria are the main sites of ATP and reactive oxygen species production in ischaemia-reperfusion, the lower ATP and adenine nucleotide levels and increased oxidative stress observed in cardiac grafts preserved in UW or ETK solution could be attributed to mitochondrial damage. ${ }^{39}$ In the MPO staining experiment we clearly showed that UW and ETK solutions alleviated oxidative stress in cardiomyocytes. On the other hand, apoptosis plays an essential role in the pathogenesis of heart dysfunction related to ischaemia-reperfusion, pressure overload and chronic heart failure. ${ }^{40}{ }^{41}$ Increased cardiomyocyte apoptosis results in contractile tissue loss, compensatory hypertrophy and reparative fibrosis, all of which contribute to the development of cardiovascular disease. ${ }^{42}$ Similarly, these phenomena occur in preserved hearts. Traditionally, two principal pathways to apoptosis have been recognised: the transmembrane 'extrinsic' pathway and the mitochondrial 'intrinsic' pathway. Both depend on the activation of cysteine proteases that cleave at aspartate residues (caspases). ${ }^{43}$ The initiator caspases for the extrinsic pathway are caspase- 8 and -10 , whereas caspase- 9 and -2 are initiator caspases for the intrinsic pathway. The effector caspases are believed to be similar for both pathways, namely caspase- $3,-6$ and $-7 .{ }^{44}$ Caspase- 3 immunostaining showed that UW or ETK solution inhibited apoptosis (figure $3 \mathrm{H}$ ).

The identification of new strategies to prevent cardiomyocyte injury is an important research goal in attempts to optimise the use of donor hearts for transplantation. Use of our evaluation system should help greatly to improve and develop organ preservation solutions. In conclusion, the data reported here demonstrate that the use of UW or ETK solution and the novel protocol described here may help in heart preservation. Preserving cardiac grafts in good condition by minimising viability loss before clinical heart transplantation is a major research goal in improving transplantation outcomes.

Contributors EK and TT: participated in the research design; NK and TT: wrote the manuscript; NK, TK, MM and TT: performed the research; and NK, TK, MM, EK, YI, JD and TT: analysed the data.

Funding None.

Competing interests EK is a chief scientific advisor to Otsuka Pharmaceutical Factory, Inc. There are no products in development or marketed products to declare. Dr EK's role does not alter the authors' adherence to all the Heart Asia policies on sharing data and materials. The other authors declare no competing financial interests.

Provenance and peer review Not commissioned; externally peer reviewed.

Open Access This is an Open Access article distributed in accordance with the Creative Commons Attribution Non Commercial (CC BY-NC 3.0) license, which permits others to distribute, remix, adapt, build upon this work non-commercially, and license their derivative works on different terms, provided the original work is properly cited and the use is non-commercial. See: http://creativecommons.org/ licenses/by-nc/3.0/

\section{REFERENCES}

1 Nakatani T. Heart transplantation. Circ J 2009;(Suppl A):A55-60.

2 Wiedemann $D$, Schneeberger $S$, Friedl $P$, et al. The fibrin-derived peptide Bbeta (15-42) significantly attenuates ischemia-reperfusion injury in a cardiac transplant model. Transplantation 2010:89:824-9.

3 Jahania MS, Sanchez JA, Narayan P, et al. Heart preservation for transplantation: principles and strategies. Ann Thorac Surg 1999;68:1983-7.

4 Keck BM, White R, Breen TJ, et al. Thoracic organ transplants in the United States: a report from the UNOS/ISHLT Scientific Registry for Organ Transplants. United Network for Organ Sharing, International Society for Heart and Lung Transplantation. Clin Transp/ 1994;37-46.

5 George TJ, Arnaoutakis GJ, Baumgartner WA, et al. Organ storage with University of Wisconsin solution is associated with improved outcomes after orthotopic heart transplantation. J Heart Lung Transplant 2011;30:1033-43.

6 George TJ, Arnaoutakis GJ, Merlo CA, et al. Association of operative time of day with outcomes after thoracic organ transplant. JAMA 2011;305:2193-9.

7 Rudd DM, Dobson GP. Eight hours of cold static storage with adenosine and lidocaine (Adenocaine) heart preservation solutions: toward therapeutic suspended animation. J Thorac Cardiovasc Surg 2011;142:1552-61.

8 Steering Committee of the Istanbul Summit. Organ trafficking and transplant tourism and commercialism: the Declaration of Istanbul. Lancet 2008;372:5-6. 
9 Boucek MM, Mashburn C, Dunn SM, et al. Pediatric heart transplantation after declaration of cardiocirculatory death. N Engl J Med 2008;359:709-14.

10 Guan Q, Li S, Yip G, et al. Decrease in donor heart injury by recombinant clusterin protein in cold preservation with University of Wisconsin solution. Surgery 2012;151:364-71.

11 Alves MG, Oliveira PF, Martins FO, et al. Gender-dependent metabolic remodeling during heart preservation in cardioplegic celsior and histidine buffer solution. J Cardiovasc Pharmacol 2012;59:151-7.

12 Higashi H, Takenaka K, Fukuzawa K, et al. Restoration of ATP contents in the transplanted liver closely relates to graft viability in dogs. Eur Surg Res 1989;21:76-82.

13 Sasaki K, Hirata K, Zou XM, et al. Optimum small bowel preservation solutions and conditions: comparison of UW solution and saline with or without glutamine. Transplant Proc 1996:28:2620-1.

14 Belzer FO, Southard JH. Principles of solid-organ preservation by cold storage. Transplantation 1988:45:673-6.

15 Suehiro K, Mohri M, Takagaki M, et al. The effect of graft perfusion with warm blood cardioplegia for cadaver heart transplantation. Surg Today 1999;29:890-6

16 Schlachter K, Kokotilo MS, Carter J, et al. Redefining the properties of an osmotic agent in an intestinal-specific preservation solution. World J Gastroenterol 2010:16:5701-9.

17 Maathuis $\mathrm{MH}$, Leuvenink HG, Ploeg RJ. Perspectives in organ preservation. Transplantation 2007:83:1289-98.

18 Kim JS, He L, Qian T, et al. Role of the mitochondrial permeability transition in apoptotic and necrotic death after ischemia/reperfusion injury to hepatocytes. Curr Mol Med 2003;3:527-35.

19 Hakamata Y, Murakami T, Kobayashi E. "Firefly rats" as an organ/cellular source for long-term in vivo bioluminescent imaging. Transplantation 2006;81:1179-84.

20 Teratani T, Kobayashi $\mathrm{E}$. In vivo bioimaging rats for translational research in cell/tissue transplantation. Cell Med 2012;3:3-11.

21 Negishi $\mathrm{K}$, Teratani T, Iwasaki J, et al. Luminescence technology in preservation and transplantation for rat islet. Islets 2011:3:111-17.

22 Teratani T, Kasahara N, Doi J, et al. Use of Mesenchymal Stem Cell-conditioned Medium to Activate Islets in Preservation Solution. Cell Med 2012; in press.

23 Iwai S, Kikuchi T, Kasahara N, et al. Impact of normothermic preservation with extracellular type solution containing trehalose on rat kidney grafting from a cardiac death donor. PLOS ONE 2012;7:e33157.

24 Xiu D, Uchida $\mathrm{H}$, To $\mathrm{H}$, et al. Simplified method of heterotopic rat heart transplantation using the cuff technique: application to sublethal dose protocol of methotrexate on allograft survival. Microsurgery 2001;21:16-21.

25 Shimizu H, Takahashi M, Kaneko T, et al. KRP-203, a novel synthetic immunosuppressant, prolongs graft survival and attenuates chronic rejection in rat skin and heart allografts. Circulation 2005;111:222-9.

26 Enosawa S, Baird MA, Heslop BF. Two methods of heterotopic heart-grafting in rats compared. Transplantation 1991:51:1320-2.
27 Aguiar MI, Farias DR, Pinheiro ML, et al. Quality of life of patients that had a heart transplant: application of Whoqol-Bref scale. Arq Brs Cardiol 2011;96:60-8.

28 Cooly DA, Bloodwell RD, Hallman GL, et al. Organ transplantation for advanced cardiopulmonary disease. Ann Thorac Surg 1969;8:30-46.

29 Wang $\mathrm{CY}$, Aronson I, Takuma S, et al. cAMP pulse during preservation inhibits the late development of cardiac isograft and allograft vasculopathy. Circ Res 2000;86:982-8.

30 Alexander JW, Zola JC. Expanding the donor pool: use of marginal donors for solid organ transplantation. Clin Transplant 1996;10:1-19.

31 Rahmani M, Cruz RP, Granville DJ, et al. Allograft vasculopathy versus atherosclerosis. Circ Res 2006:99:801-5.

32 Thatte HS, Rousou L, Hussaini BE, et al. Development and evaluation of a novel solution, Somah, for the procurement and preservation of beating and nonbeating donor hearts for transplantation. Circulation 2009;120:1704-13.

33 Cobert ML, Peltz M, West LM, et al. Importance of organ preservation solution composition in reducing myocardial edema during machine perfusion for heart transplantation. Transplant Proc 2010;42:1591-4.

34 Aupperle H, Garbade J, Ullmann C, et al. Comparing the ultrastructural effects of two different cardiac preparation- and perfusion-techniques in a porcine model of extracorporeal long-term preservation. Eur J Cardiothorac Surg 2007;31:214-21

35 McMahon T. Size and shape in biology. Science 1973;179:1201-4.

36 Qiu L, Chen C, Ding G, et al. The effects of electromagnetic pulse on the protein levels of tight junction associated-proteins in the cerebral cortex, hippocampus, heart, lung, and testis of rats. Biomed Environ Sci 2011;24:438-44.

37 Lisewski $U$, Shi $Y$, Wrackmeyer $U$, et al. The tight junction protein CAR regulates cardiac conduction and cell-cell communication. J Exp Med 2008;205:2369-79.

38 Kostin S. Zonula occludens-1 and connexin 43 expression in the failing human heart. J Cell Mol Med 2007;11:892-5.

39 Ben, Mosbah I, Roselló-Catafau J, Alfany-Fernandez I, et al. Addition of carvedilol to University Wisconsin solution improves rat steatotic and nonsteatotic liver preservation. Liver Transp/ 2010;16:163-71.

40 Movassagh M, Foo RS. Simplified apoptotic cascades. Heart Fail Rev 2008:13:111-19.

41 Morrissy $\mathrm{S}, \mathrm{Xu} \mathrm{B}$, Aguilar $\mathrm{D}$, et al. Inhibition of apoptosis by progesterone in cardiomyocytes. Aging Cell 2010;9:799-809.

42 Son NH, Yu S, Tuinei J, et al. PPAR $\gamma$-induced cardiolipotoxicity in mice is ameliorated by PPAR $\alpha$ deficiency despite increases in fatty acid oxidation. J Clin Invest 2010;120:3443-54

43 Zhang XD, Gillespie SK, Borrow JM, et al. The histone deacetylase inhibitor suberic bishydroxamate: a potential sensitizer of melanoma to TNF-related apoptosis-inducing ligand (TRAIL) induced apoptosis. Biochem Pharmacol 2003;66:1537-45.

44 Xia $D$, Shen $K$, Zhong $W$, et al. Administration of minocycline ameliorates damage in a renal ischemia/reperfusion injury model. Clin Invest Med 2011;34: E55-63. 